\title{
New record and supplemental description of Alainopaguroides andamanensis McLaughlin (Decapoda: Anomura: Paguridae) from Japan and Indonesia
}

\section{Tomoyuki Komai and Patsy A. McLaughlin}

\begin{abstract}
A poorly known pagurid hermit crab, Alainopaguroides andamanensis McLaughlin, 2002, is recorded from Japanese and Indonesian waters for the first time. This species was only recently described from the Andaman Sea near Phuket, Thailand. The original description of the species was based on small, damaged specimens, and therefore a supplemental description based on the newly obtained specimens is provided. A sufficient comparison with the other congeneric species, A. lemaitrei McLaughlin, 1997, is now possible. Alainopaguroides andamanensis was found to use halves of bivalve shells as protective coverings.
\end{abstract}

\section{Introduction}

In a review of the hermit crab fauna of southern Thailand, McLaughlin (2002) described a new species of the hermit crab genus Alainopaguroides McLaughlin, 1997, A. andamanensis, based on material collected from the Andaman Sea during the 1996-1998 BIOSHELF Program, a joint survey conducted by the Phuket Marine Biological Center, the Zoological Museum of the University of Copenhagen, and DANIDA (the Danish foreign aid organization). Although the material contained 34 specimens, very few of the specimens had any appendages. A moderately small female in poorly calcified condition was designated as the holotype, because it was the only specimen with a cheliped, the left, and both third pereopods attached to the body. Two other specimens, both males, were selected as paratypes. Because of the rather poor condition of the specimens available for study, comparison with the other congeneric species, A. lemaitrei McLaughlin, 1997, remained insufficient, although there was little doubt that they were specifically distinct. One of us (PMcL) subsequently found an Indonesian specimen from the Siboga Expedition that, while sharing certain characters with $A$. andamanensis, differed in others, and consequently was identified only tentatively as that species (McLaughlin, personal observation).

During recent oceanographic cruises to the Nansei Islands in southern Japan, including the Osumi Islands, Amami Islands, and Okinawa Islands, many specimens of a pagurid species referable to Alainopaguroides andamanensis, were collected. The single male from the Siboga Expedition provided evidence of clinal variation in armature of the appendages that permitted us to conclude that $A$. andamanensis occurred not only in the Andaman Sea, but in Indonesian and Japanese waters as well. We provide here a supplemental description based on this additional material. This material enables us to make a comparison with $A$. lemaitrei. A brief note on the ecology of $A$. andamanensis is also provided, based on observations made on shipboard.

With the exception of the Siboga specimen that is being returned to the Instituut voor Taxonomische Zoologie (Zoologisch Museum), Universiteit van Amsterdam, Amsterdam, The Netherlands (ZMA), the 
specimens examined in this study are deposited in the Natural History Museum and Institute, Chiba (CBM), Muséum national d'Histoire naturelle, Paris (MNHN), and National Museum of Natural History, Smithsonian Institution, Washington D.C. (USNM). The shield length (sl), measured from the tip of rostrum (rostral lobe) to the midpoint of posterior margin of the shield provides an indication of animal size. For detailed observation of the surface structure on the integument, the specimens (including removed appendages) were stained with a methylene blue solution. The general terminology used in the description is that of McLaughlin (2003), with the exception of pleon for abdomen (Schram \& Koenemann, 2004) and numbered thoracic sternites. The drawings were made with the aid of a drawing tube mounted on a Leica MZ8 stereomicroscope.

\section{Taxonomic Account}

\section{Alainopaguroides andamanensis} McLaughlin, 2002

(Figs. 1-56)

Alainopaguroides andamanensis McLaughlin, 2002: 434, fig. 7A-E.

Material examined. - TRV Toyoshiomaru, 1996-05 cruise: station 9, N of Yakushima Island, $30^{\circ} 27.80^{\prime} \mathrm{N}, 130^{\circ} 35.30^{\prime} \mathrm{E}$, $95 \mathrm{~m}$, sledge net, coll. T. Komai, 8 males (sl $1.5-2.5 \mathrm{~mm}$ ), 1 female (sl $1.7 \mathrm{~mm}$ ), 5 ovigerous females (sl 2.1-2.4 mm), CBM-ZC 6625 . TRV Toyoshio-maru, 1997-05 cruise, station $14, \mathrm{~N}$ of Yakushima Island, $30^{\circ} 32.00^{\prime} \mathrm{N}$, $130^{\circ} 49.00^{\prime} \mathrm{E}, 77 \mathrm{~m}$, 4 June 1997, sledge net, coll. T. Komai, male (sl $2.4 \mathrm{~mm}$ ), CBM-ZC 6623; same data, 4 males (sl 2.2-2.8 mm), 9 ovigerous females (sl 2.3-2.7 mm), CBM-ZC 6624; same data, 1 male (sl $2.5 \mathrm{~mm}$ ), 1 ovigerous female (sl $2.5 \mathrm{~mm}$ ), MNHN-Pg; same data, 1 male (sl. $2.6 \mathrm{~mm}$ ), 1 ovigerous female (sl $2.3 \mathrm{~mm}$ ), USNM. TRV Toyoshiomaru, 1998-04 cruise, stn 4, east of Yakushima Island, $30^{\circ} 14.50^{\prime} \mathrm{N}, 130^{\circ} 44.60^{\prime} \mathrm{E}$,
76 m, 17 May 1998, dredge, coll. T. Komai, 1 ovigerous female (sl $2.4 \mathrm{~mm}$ ), CBM-ZC 8349. RV Tansei-maru, KT96-06 cruise: station KM-06, off Kushimoto, Kii Peninsula, 69-72 m, 14 May 1996, coll. E. Tsuchida, 1 female (sl $2.4 \mathrm{~mm}$ ), CBM-ZC 6626; RV Tansei-maru, KT02-03 cruise, station E-6, Kerama Islands, Ryukyu Islands, $26^{\circ} 15.33^{\prime} \mathrm{N}, 127^{\circ} 15.97$ 'E, 95-57 m, 19 April 2002, dredge, coll. T. Komai, 1 male (sl 2.4 $\mathrm{mm}), \mathrm{CBM}-Z \mathrm{C} 6627$.

Siboga station $49 \mathrm{a}$, Indonesia, $08^{\circ} 23.5^{\prime} \mathrm{S}$, $119^{\circ} 04.6^{\prime} \mathrm{E}$, depth not recorded, 14 April 1899, 1 male (sl $2.1 \mathrm{~mm}$ ), ZMA.

Supplemental description. - Carapace vaulted. Shield (Fig. 1A) 1.0-1.1 times broader than long; dorsal surface convex, with irregular submedian and dorsolateral rows of short stiff setae, lateral portions additionally with shorter scattered setae; anterolateral portions somewhat depressed; anterior margin between rostrum and lateral projections slightly concave; no postrostral depression; lateral margins strongly convex. Rostral lobe broadly rounded. Lateral projections each with strong marginal spine usually overreaching rostral lobe. Posterior carapace (Fig. 1B) membranous; linea transversalis covered by calcified, rod-like plate; cardiac sulci and sulci cardiobranchialis apparently absent, but traces of obliquely longitudinal lines visible on either side of cardiac region throughout integument; branchial regions inflated, with short to long setae, longest and most abundant laterally.

Ocular peduncles (including corneas) (Fig. 1A) short, exceeding half length of shield, enlarged distally with well dilated corneas; corneal width about half of length of ocular peduncle; dorsal surfaces each with row of setae along base of cornea and 1 tuft of minute spiniform bristles medially. Ocular acicles widely separated basally, $0.4-0.7$ length of ocular peduncles (including corneas), slender, narrowly elongate and triangular, terminating acutely; dorsal surfaces nearly flat. Inter-ocular lobe clearly visible in dorsal view, with slightly concave 


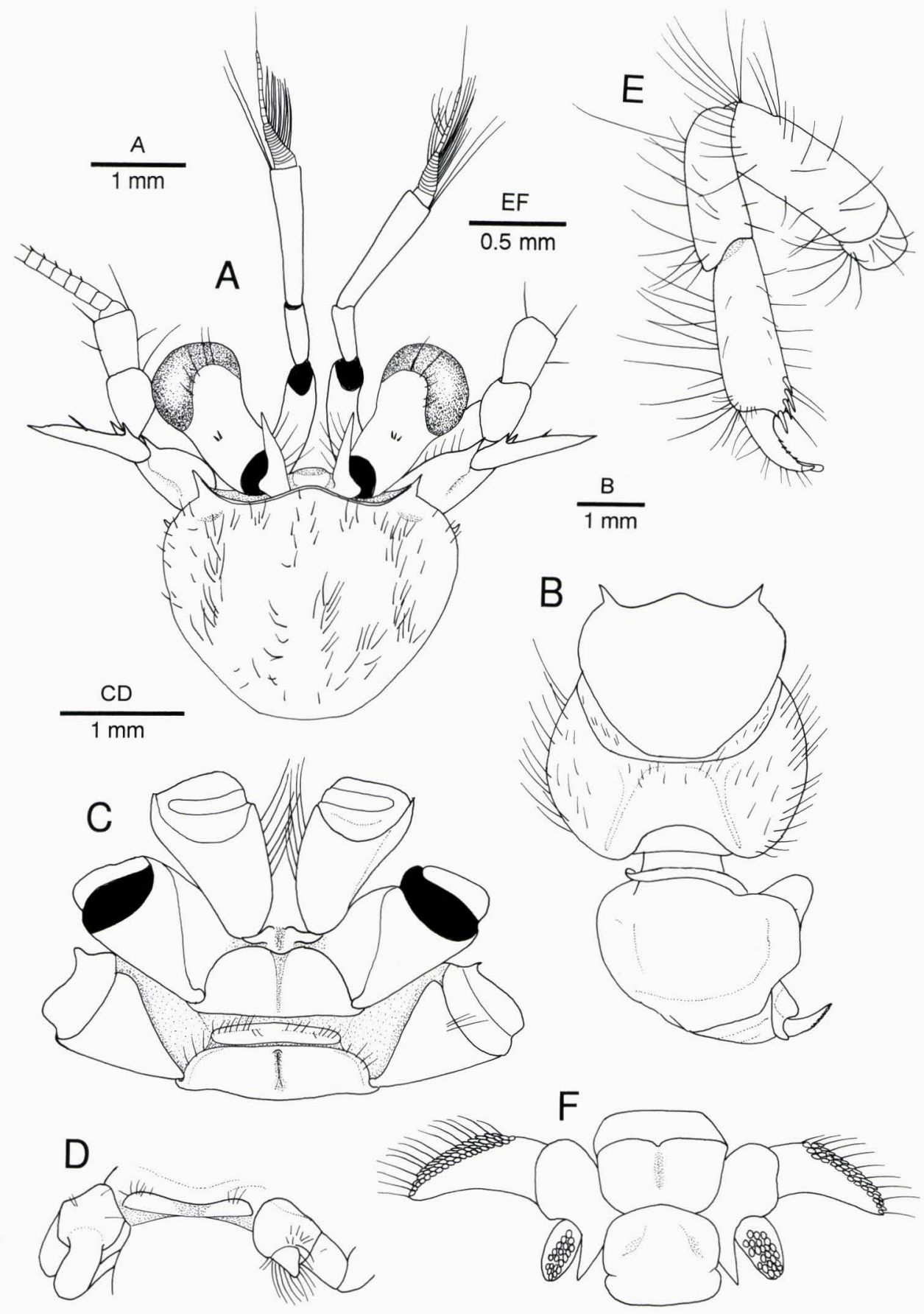

Fig. 1. Alainopaguroides andamanensis McLaughlin, 2002. A, shield and cephalic appendages, dorsal view; $\mathrm{B}$, carapace and abdomen, dorsal view, right sexual tube is shown; $\mathrm{C}$, fourth to sixth thoracic sternites and coxae of first to third pereopods, ventral view; $\mathrm{D}$, eighth thoracic sternite and coxae of fifth pereopods, ventral view; E, left fourth pereopod, lateral view; F, sixth abdominal tergite, telson and uropods, dorsal view. Male from off Yakushima Island (sl $2.4 \mathrm{~mm}$; CBM-ZC 6623). 
anterior surface.

Antennular peduncles (Fig. 1A) long, overreaching ocular peduncles by $0.3-0.5$ of penultimate segments. Ultimate segment 1.2-1.3 times as long as penultimate segment, increasing in width distally in dorsal and lateral views, with rows of very short setae on dorsal surface. Basal segment subequal in length to penultimate segment, unarmed, but with statocyst lobe somewhat enlarged.

Antennal peduncles (Fig. 1A) overreaching ocular peduncles (including corneas) by 0.3-0.5 length of fifth segments. Fifth segment stout, 1.5-2.0 times longer than wide, with few long spiniform setae distally. Fourth segment with 1 long seta mesially. Second segment with dorsolateral distal angle produced, terminating in slender spine; dorsomesial distal angle with prominent spine. First segment with 1 prominent spine on ventrodistal margin lateral to antennal gland opening. Antennal acicle reaching distal margin of fifth segment, slightly overreaching distal margin of cornea, nearly straight; mesial margin with 1 or 2 subproximal spines proximally and 1 spiniform bristle at about midlength and additional few short setae.

Mandible (Fig. 2A) with 2 widely separated, acute teeth on mesial edge of incisor process; distal article of palp small. Maxillule (Fig. 2B) with coxal endite truncate distally and bearing 4 or 5 curved bristles; basial endite somewhat elongate, with 2 rows of spines on slightly convex mesial margin; endopod slender, tapering distally, with 1 apical bristle. Maxilla (Fig. 2C) rather broad; endopod slender, nearly reaching distal end of basial endite; anterior lobe of scaphognathite short. First maxilliped (Fig. 2D) with moderately slender endopod palp slightly overreaching distal margin of elongate oval basial endite; exopod long, proximolateral margin slightly expanded. Second maxilliped (Fig. 2D) with basis-ischium fusion incomplete; exopod elongate. Third maxilliped (Fig. 2F) long, slender, moderately setose; basis and ischium not fused sepa- rated by distinct suture; propodus slightly longer than merus; carpus unarmed on dorsodistal margin; merus with large spine on dorsodistal margin, but ventromesial margin unarmed; ischium (Fig. 2G) with poorly developed crista dentata composed of row of 5 or 6 triangular teeth of various size and 1 or 2 accessory teeth arising adjacent to dorsomesial margin; basis with 3 acute teeth on mesial margin; exopod long, reaching nearly to distal margin of carpus.

Right cheliped (Figs. 3A, C, 4A, B) slightly shorter to distinctly longer, and always stouter than left, sexually dimorphic; carpus and merus somewhat compressed laterally. Chela elongate, 3.6-4.3 times as long as wide in males, 4.6-4.7 times as long in females. Dactylus $0.6-0.8$ length of palm; dorsal surface with row of tufts of setae along cutting edge and few setae medially, dorsomesial margin not delimited; mesial and ventral surfaces with tufts of short to moderately long setae; cutting edge of males bearing 2 broad calcareous teeth, terminating in small corneous claw; cutting edge of females with 2 obsolete calcareous teeth in proximal 0.6 and row of minute corneous teeth in distal 0.4. Palm elongate, slightly broader distally, 1.4-1.5 length of carpus in males, 0.6-0.8 in females; dorsal surface slightly convex, unarmed, dorsomesial and dorsolateral margins not delimited; lateral and mesial faces not spinulose; ventral surface slightly convex, unarmed, with rows of long setae distally extending onto fixed finger. Fixed finger with row of tufts of short setae on dorsal surface; cutting edge of males bearing 2 broad, occasionally obsolete teeth, terminating in small corneous claw; cutting edge of females with 2 or 3 obsolete teeth in proximal $0.7-0.8$ and with row of minute corneous teeth in distal $0.2-0.3$. Carpus 0.6-0.8 length of merus in males, subequal in length to merus in females; dorsomesial and dorsolateral margins each with row of small spines decreasing in size proximally; dorsal surface with shallow longitudinal sulcus, unarmed; lateral, mesial and ventral surfaces not spinose, with few short 

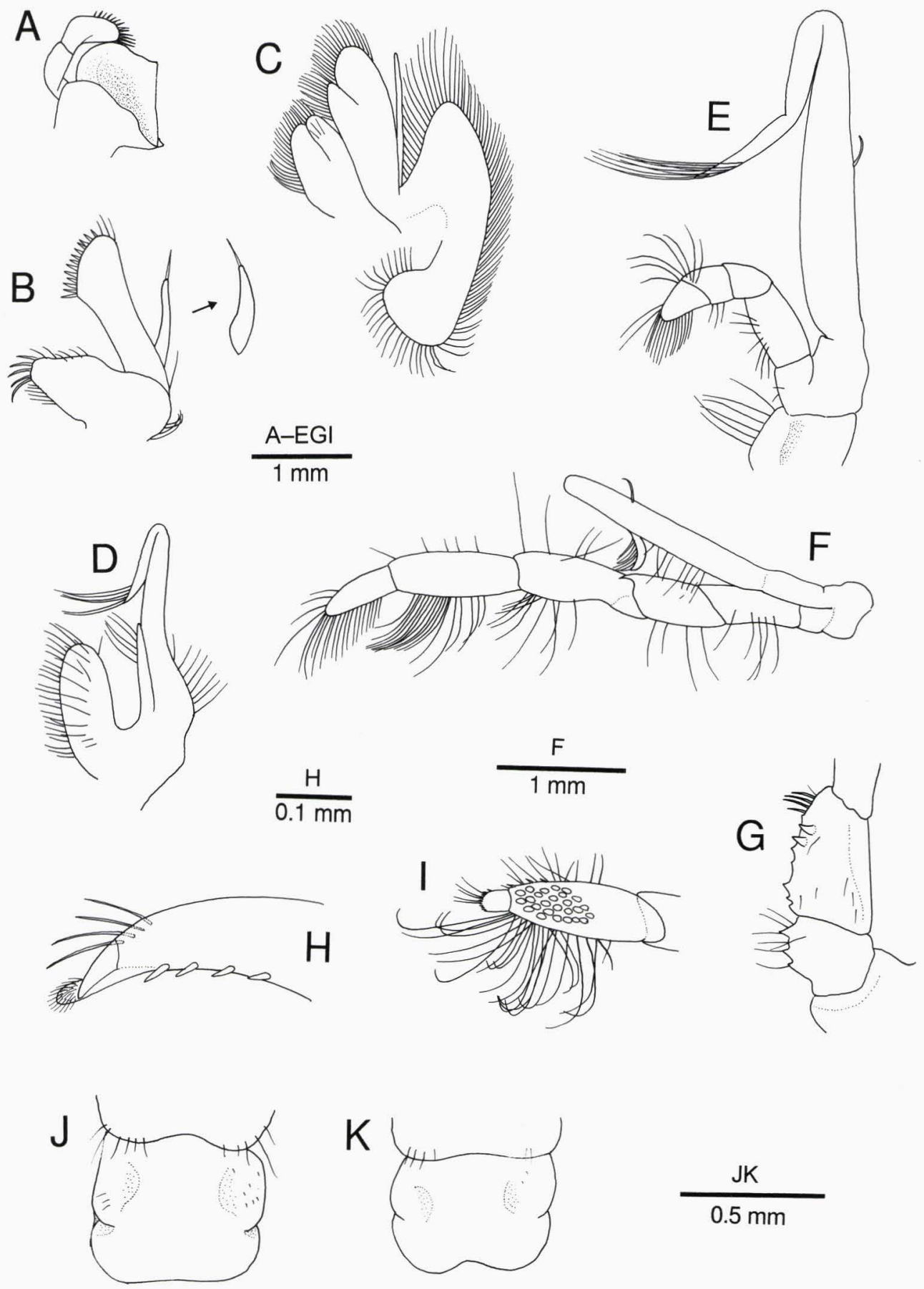

Fig. 2. Alainopaguroides andamanensis McLaughlin, 2002. Left appendages and telson. A, mandible, dorsal view; B, maxillule, ventral view; inset, endopod, lateral view; C, maxilla, ventral view; $\mathrm{D}$, first maxilliped, ventral view; E, second maxilliped, ventral view; $\mathrm{F}$, third maxilliped, lateral view; $\mathrm{G}$, ischium and basis of third maxilliped, ventral view; H, distal part of dactylus of fourth pereopod, lateral view; I, chela of fifth pereopod, lateral view; J, K, telson, dorsal view. A-J, male from off Yakushima Island (sl $2.4 \mathrm{~mm}$; CBM-ZC 6623); K, male from $\mathrm{N}$ of Yakushima Island (sl $2.2 \mathrm{~mm}$; CBM-ZC 6625). 

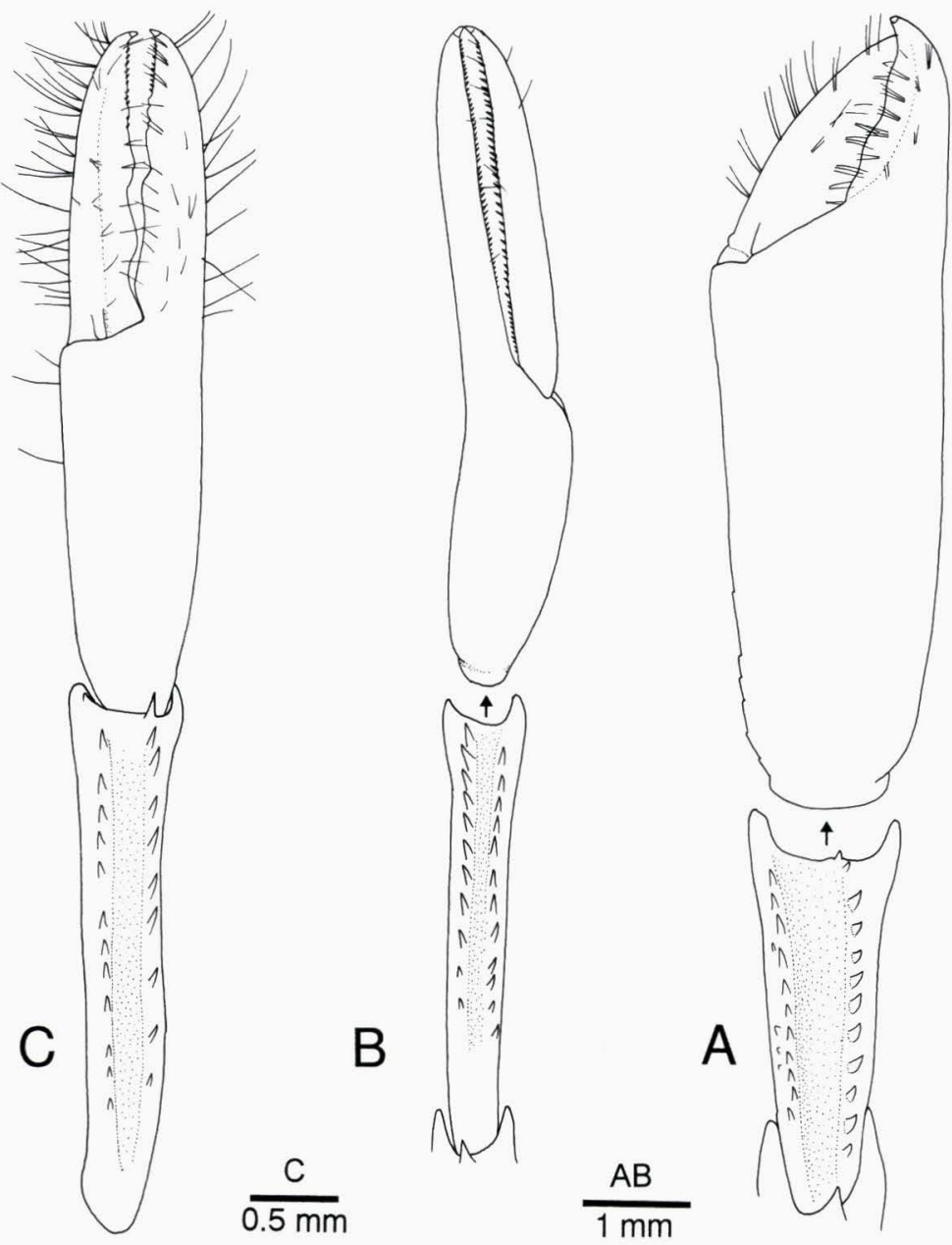

Fig. 3. Alainopaguroides andamanensis McLaughlin, 2002. A, C, right chela and carpus, dorsal view; B, left chela and carpus, dorsal view. A, B, male from off Yakushima Island (sl $2.4 \mathrm{~mm}$; CBM-ZC 6623); C, female from same locality (sl $2.4 \mathrm{~mm}$; CBM-ZC 6624).

setae. Merus with 1 large dorsodistal spine; dorsal surface with very short transverse rows of short bristles; lateral face not spinulose, ventrolateral margin with irregular single or double row of small spines, 1 more prominent spine at distal angle; mesial face not spinose, but with row of small spines or spinulose tubercles adjacent to ventromesial margin, ventromesial margin spinulose or with distinct row of small spines, 1 larger spine at distal angle; ventral surface slightly concave, without setae. Ischium with con- spicuous blunt projection dorsally; ventromesial margin with 1 or 2 small spines medially; ventrolateral angle with 1 small spine and few bristles. Coxa with small spine on ventromesial distal angle.

Left cheliped (Figs. 3B, 4C, D) occasionally overreaching right cheliped by as much as half length of dactylus in both males and females. Chela weakly compressed dorsoventrally, 1.1-1.4 length of carpus; fingers nearly straight, fixed finger slightly deflexed. Dactylus long, 1.1-1.8 length of 


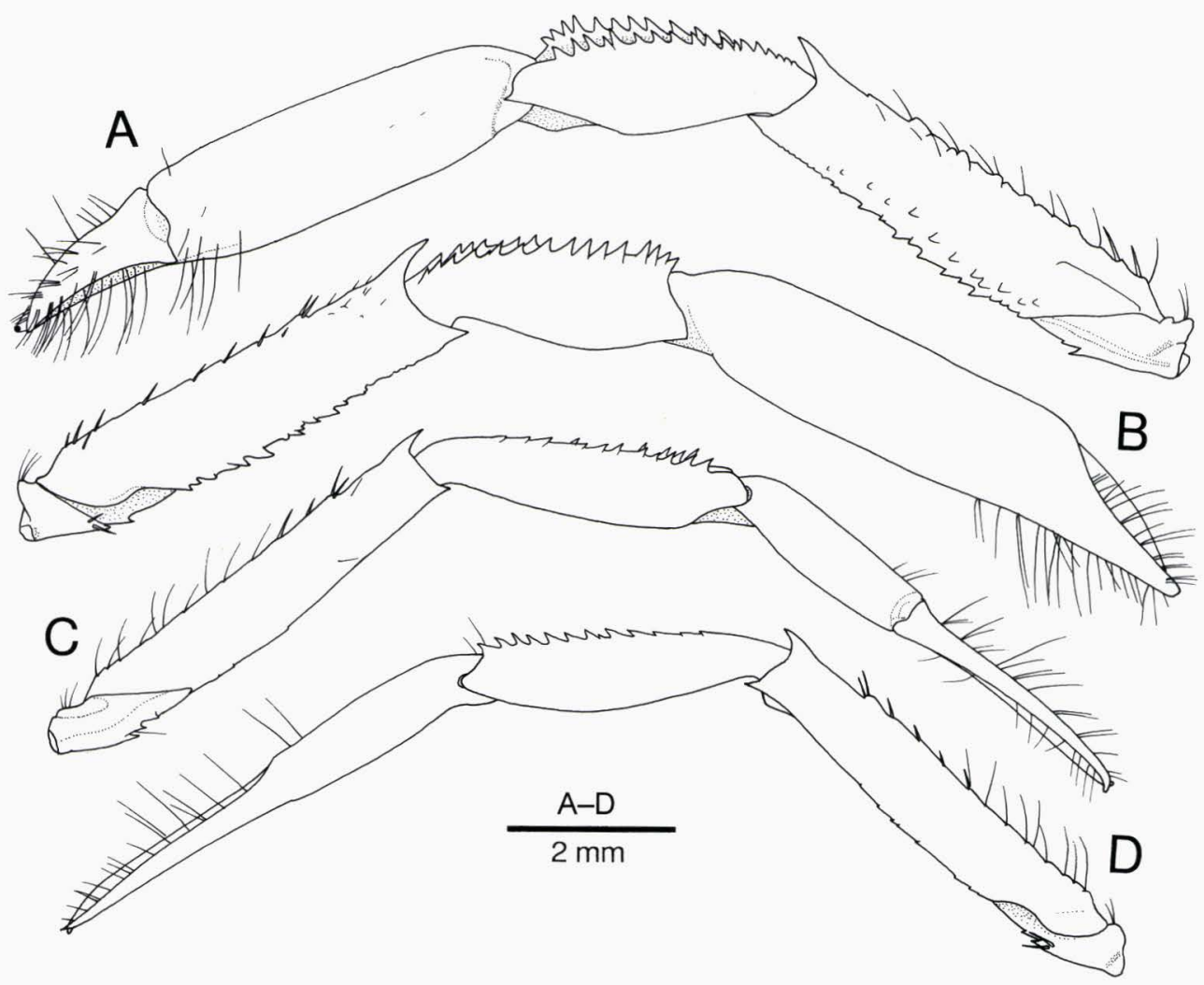

Fig. 4. Alainopaguroides andamanensis McLaughlin, 2002. Chelipeds. A, right cheliped, mesial view; B, same, lateral view; C, left cheliped, mesial view; D, same, lateral view. Male from off Yakushima Island (sl $2.4 \mathrm{~mm}$; CBM-ZC 6623).

palm; dorsomesial margin smooth; cutting edge with row of tiny corneous teeth, terminating in small, strongly curved corneous claw. Palm $0.5-0.7$ length of carpus; dorsal surface slightly convex, without delineation of dorsolateral or dorsomesial margins; lateral, mesial and ventral surfaces with few short setae. Fixed finger slightly to somewhat deflexed laterally; cutting edge with row of closely-spaced small corneous teeth. Carpus 0.7-0.9 length of merus, narrowly subrectangular in dorsal view, somewhat compressed laterally; dorsolateral and dorsomesial margins weakly elevated, each with row of small slender spines (6-15 spines on dorsolateral margin, $8-12$ spines on dorsomesial margin), dorsal surface unarmed; lateral and mesial faces nearly perpendicu- lar, unarmed; ventral surface unarmed. Merus with large dorsodistal spine; dorsal surface flattened, with row of very short transverse ridges and short spiniform bristles on distal half and setae on proximal half; ventrolateral margin with row of widelyspaced minute spines; ventromesial margin with row of widely-spaced spinules; ventral surface slightly concave, unarmed. Ischium with 2 or 3 small but distinct spines on ventromesial margin; dorsal surface with low protuberance; ventrolateral distal angle usually with 1 small spine and few spiniform bristles. Coxa similar to that of right cheliped.

Ambulatory legs (second and third pereopods) (Fig. 5A, B) long, generally similar, right second overreaching right cheliped by 


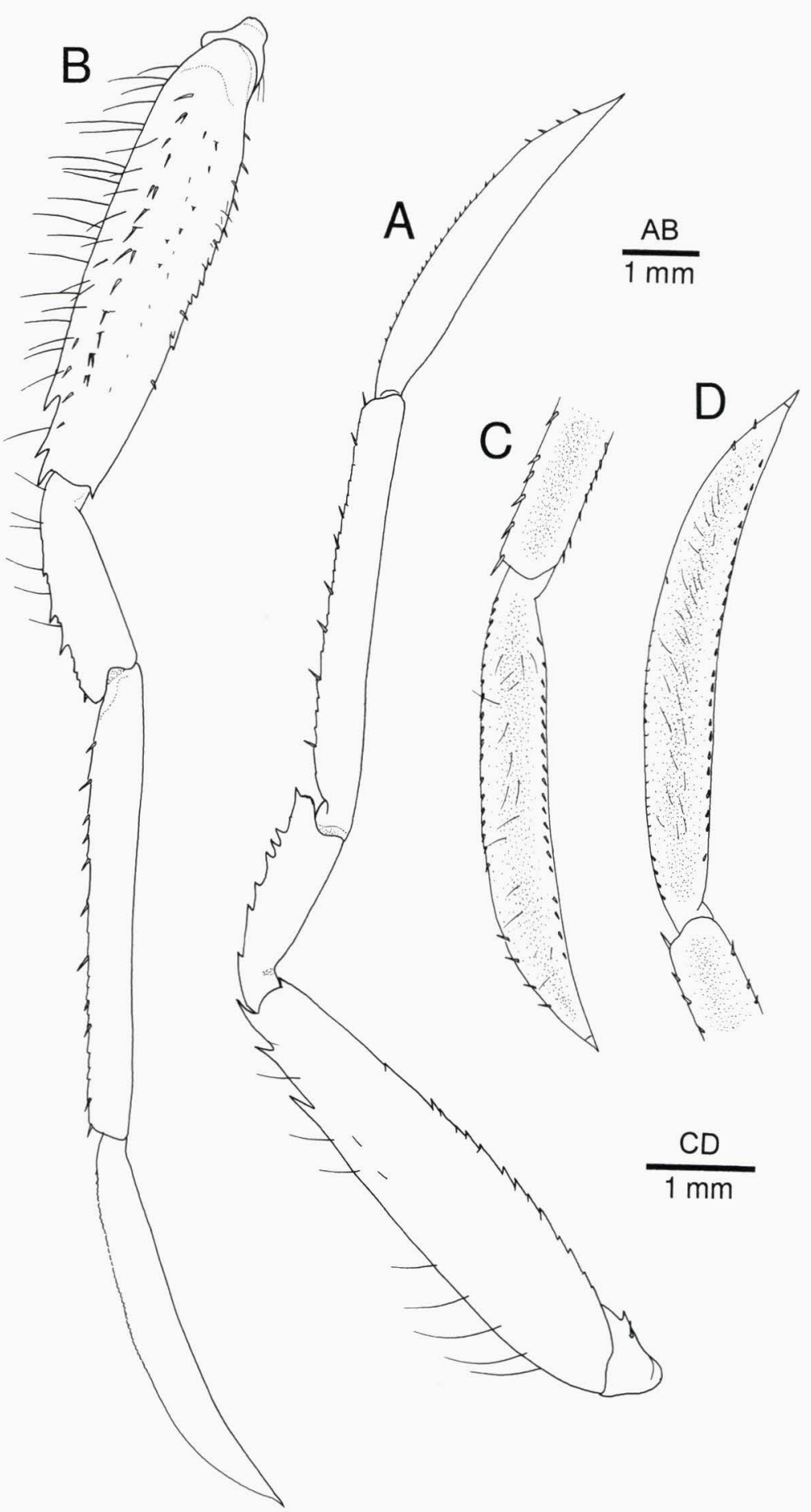

Fig. 5. Alainopaguroides andamanensis McLaughlin, 2002. A, right second pereopod, lateral view; B, left third pereopod, lateral view; C, dactylus of right second pereopod, mesial view; D, dactylus of left third pereopod, mesial view. Male from off Yakushima Island (sl $2.4 \mathrm{~mm}$; CBM-ZC 6623). 
half to full length of dactylus. Dactyli (Fig. 5C, D) distinctly blade-shaped, 0.7-0.9 length of propodi, strongly compressed laterally, slightly twisted in dorsal view, slightly curved ventrally in lateral view; dorsal margins each with row of more than 20 spinules slightly increasing in size distally; lateral faces nearly flattened; mesial faces concave, with scattered short setae medially; ventromesial margins each with row of about 20 spinules. Propodi 1.7-2.0 length of carpi, somewhat compressed laterally; dorsal surfaces minutely serrate, each bearing row of widely-spaced, slender corneous spinules. Carpi 0.4-0.6 length of meri; dorsal surfaces each with 4-8 small spines usually distributed over entire length and occasionally with additional minute serrations. Meri each with 2-4 small but conspicuous spines on dorsal surface in distal $0.2-0.3$, remaining dorsal surface with row of sparse long setae, but not spinulose; lateral faces of second nearly flattened, third noticeably convex, former only with few very short setae, but latter with 2 rows of short spiniform bristles dorsally and minute setae ventrally, and sometimes with small spines adjacent to ventral margin; ventral surface armed with single or double row of small spines or spinulose tubercles laterally, but unarmed or only with few small spines mesially, and with short spiniform bristles on third. Ischia of second unarmed, third each armed with 1 small subdistal spine on ventral face. Coxae unarmed; paired gonopores present in females.

Fourth pereopods (Fig. 1E) slender, semichelate. Each dactylus weakly curved laterally in dorsal view, somewhat curved ventrally in lateral view, terminating in small corneous claw, with row of 4 minute corneous spinules on ventral margin; preungual process (Fig. $2 \mathrm{H}$ ) well developed, reaching beyond and crossed by claw, bearing numerous short setae. Propodus elongate, slightly broader distally, with 4-6 slender spines arranged in single row on ventrodistal margin.

Fifth pereopods chelate. Propodi each with rasp consisting of well-spaced scales
(Fig. 2I). Males with long right sexual tube oriented toward exterior, then recurved over anterior part of pleon (Fig. 1B, D); left sexual tube short (Fig. 1D).

Thoracic sternites broad (Fig. 1C, D). Anterior lobe of sixth thoracic sternite (Fig. 1C) very narrowly subrectangular, with sparse setae on ventral surface. Eighth thoracic sternite (Fig. 1D) composed of widely separated lobes, each with few setae anteriorly.

Pleon (cf. Schram \& Koenemann, 2004) (Fig. 1B) reduced, heart-shaped. Tergal plates of second through fifth pleomeres very faintly delineated. Tergite of sixth pleomere weakly calcified, subdivided into moderately broad anterior lobe, and posterior pair of broad plates separated by distinct median groove. No paired or unpaired pleopods in males. Females with no paired pleopods, but unpaired left biramous pleopods on second to fourth pleomeres. Uropods (Fig. 1F) symmetrical; protopods each with posteromesial corner strongly produced, terminating in spine. Telson (Fig. 2J, K) subrectangular, with faint to distinct lateral indentations; posterior lobe entire or slightly divided in two lobes by very shallow median concavity, unarmed on posterior margin.

Coloration in life.- Shield generally pale reddish brown, darker medially. Posterior carapace with patches of reddish brown on anterolateral and submedian parts. Ocular peduncles reddish brown, without conspicuous markings. Antennular and antennal peduncles translucent, with red chromatophores. Chelipeds and ambulatory legs translucent with red chromatophores; fingers of right cheliped with orangish tint; carpi of both chelipeds brownish; meri of ambulatory legs each with broad, reddish brown transverse band medially.

Ecology.- The animals were collected from sandy substrates. Most of the specimens examined were found using halves of shells of various bivalve mollusks. The shells, grasped by the semichelate fourth pereopods, fully covered the pleon, but the 
anterior part of the carapace was exposed. No specimens using gastropod shells for protective coverings were encountered during field survey. The hermits moved quickly. When disturbed, they jumped backward using the blade-shaped dactyls of the ambulatory legs.

Distribution.- Southern Japan from Kii Peninsula to Ryukyu Islands; Indonesia; Andaman Sea off Phuket, Thailand; at depths of 6 49-95 m.

Remarks.- In her original description, McLaughlin (2002: 436, Fig. 7A) clearly stated that the illustrated shield and cephalic appendages were of one of the male paratypes; however, the legend for that figure identified the shield as belonging to the female holotype. The shield length of the illustrated specimen indicates that it correctly should have been cited as the male paratype from BIOSHELF station A3.

The Japanese and Indonesian specimens generally agree with the original description of Alainopaguroides andamanensis in many diagnostic aspects. However, some discrepancies have been noted. The spine on the anterolateral projections on the shield overreaches the rostral lobe in the Japanese and Indonesian specimens. McLaughlin (2002: 434) noted "Lateral projections well developed, with very prominent, long spine", but according to the illustration of the shield (McLaughlin, 2002, fig. 7A), the spines on the lateral projections only reaches to the level of the rostral lobe. The dactylus of the left chela is distinctly longer than the palm in the Indonesian and Japanese specimens, rather than approximately subequal in the holotype. The carpus of the left cheliped is armed with six or more spines on both dorsolateral and dorsomesial margins in the Japanese and Indonesian specimens, rather than bearing four spines only on the distal half of the dorsolateral margin in the holotype. The carpus of the second pereopod is armed dorsally with a row of small spines over the entire length in the Japanese specimens, the distal half in the Indonesian specimen, but the left second pereopod of one of the paratypes is unarmed except for the small dorsodistal spine. The merus of the second pereopod is armed dorsally with three or four subdistal spines in the Japanese specimens and, two in the Indonesian specimen, while the presence of only one subdistal spine is noted in the original description. The merus of the third pereopod is armed with a single or double row of small spines on the ventral surface laterally in the Japanese specimens, one row in the Indonesian specimen, as opposed to being unarmed in the illustrated paratype specimens. The telsons of the Japanese specimens have faint to distinct lateral indentations; these indentations are weak in the Indonesian specimen. Division of the telson into anterior and posterior lobes was described and illustrated for the Thai specimens as being only faint., which are said to be absent in the original description.

As previously indicated, the holotype was designated because it was the only specimen with the left cheliped and both third pereopods attached to the body. The two male paratypes (sl 1.8, $2.1 \mathrm{~mm}$ ) were the only other specimens with an intact appendage, the left second pereopod for the smaller; and the right third pereopod for the larger individual. The latter specimen ( $\mathrm{sl} 2.1 \mathrm{~mm})$ was the largest collected. The discrepancies cited between the Thai and JapaneseIndonesian specimens appear to reflect, in part, intraspecific variability and, in part, growth-related variation. For example, McLaughlin (2002) described the spines of the lateral projections as being very prominent and long. That description was based on the condition found in the majority of the bodies; however, the illustrated paratype had shorter spines than usual. The spines on the lateral projections of the Indonesian specimen, a male of the same shield length (s1 $2.1 \mathrm{~mm}$ ), are exceptionally long, indicating that intraspecific variability rather than a growth-related condition influences the length of those particular spines. The only cheliped found in the entire type series was that of the small female holotype (sl 1.4 
$\mathrm{mm})$. The smallest female in the Japanese material has a shield length of $1.7 \mathrm{~mm}$. McLaughlin (2004) has demonstrated the growth and size-related variations in the left cheliped in one species of the allied genus, Catapagurus A. Milne-Edwards, and it is reasonable to presume that the differences in the armament of the carpus seen between the holotype and the much larger Japanese females are similarly influenced. It is less clear whether intraspecific variability or growth-related variation is responsible for the differences seen in the armature of the ambulatory legs of the Thai and Japanese specimens. With such a limited sample size of appendages among the Thai specimens, within-population variability could not be assessed. Additionally there are substantial size differences between the Thai and Japanese populations. However, the single Indonesian male does provide limited evidence that intraspecific variability may be the predominant factor. That male had a partial row of spines on each of the dorsal margins of the carpi of the second pereopods, and two rather than one (Thai) or three or four (Japanese) spines on the dorsal margins of the meri. The ventral margins of the meri of the third pereopods are similarly intermediate in armature.

Alainopaguroides andamanensis differs from $A$. lemaitre $i$ in many respects. The anterolateral projections of the shield each is armed with a long, prominent spine in $A$. andamanensis, rather than a small marginal or submarginal spine or spinule as in $A$. lemaitrei. The corneas of the eyes are less dilated in $A$. andamanensis than in $A$. lemaitrei. The width of the cornea is about half of the length of the ocular peduncle in A. andamanensis, rather than approximately equal to it in $A$. lemaitrei. The ocular acicles are markedly elongate, comparable with several species of Catapagurus (see Asakura, 2001; McLaughlin, 2004), in A. andamanensis, but moderately long in $A$. lemaitrei. The antennal acicle of $A$. andamanensis is armed with one or two subproximal spines on the mesial margin, but it is unarmed in $A$. lemaitrei. The fifth segment of the antennal peduncle is distinctly stouter in A. andamanensis than in A. lemaitrei (2.0--1.5 times longer than broad versus about 4.0 times). The dactyli of the ambulatory legs in $A$. andamanensis are distinctly sabre blade-like, but those in $A$. lemaitrei are much more elongate, and not markedly blade-shaped. The dorsal surfaces of the propodi of the ambulatory legs each are armed with a row of small corneous spinules in A. andamanensis, instead of numerous short setae on those surfaces in A. lemaitrei. The posterior lobe of the telson of $A$. andamanensis is entire or slightly bilobed by a very shallow median concavity, and the posterior margin is unarmed. The telson of $A$. lemaitre $i$ has a distinct median cleft, and each oblique terminal margin bears a row of spinules.

Alainopaguroides andamanensis uses halves of bivalve shells as protective covering. However, McLaughlin (1997) reported that one specimen of the congeneric $A$. lemaitrei occupied gastropod shell well covered by anemone. Utilization of half of a bivalve shell as protective covering is known also for other pagurid species of the highly specialized genera, Alainopagurus Lemaitre \& McLaughlin, Porcellanopagurus Filhol and Solitariopagurus Türkay (Lemaitre \& McLaughlin, 1995; McLaughlin, 1997, 2000).

\section{Acknowledgements}

The senior author wishes to express his gratitude to Dr. S. Ohtsuka of Faculty of Applied Science, Hiroshima University for the invitation to participate the research cruises of the TRV Toyoshio-maru. Thanks are also extended to crews of the TRV Toyoshio-maru and of the RV Tansei-maru for their skillful collecting efforts.

\section{Literature Cited}

Asakura, A., 2001. A revision of the hermit crabs of the genera Catapagurus A. Milne Edwards and Hemipagurus Smith from the Indo-West Pacific (Crustacea: Decapoda: Anomura: 
Paguridae). Invertebrate Taxonomy, 15: 823-891.

Lemaitre, R. \& McLaughlin, P. A., 1995.

Alainopagurus crosnieri n. gen., n. sp. (Decapoda: Anomura: Paguridae) from the western Pacific. Bulletin du Muséum national d'Histoire naturelle, (4) 17A(3-4): 273-282.

McLaughlin, P. A., 1997. Crustacea Decapoda: Hermit crabs of the family Paguridae from the KARUBAR cruise in Indonesia. In: A. Crosnier \& P. Bouchet, (eds.), Résultats des campagnes MUSORSTOM, Volume 16. Mémoires du Muséum national d'Histoire naturelle, 172: 433-572.

$$
\text { 2000. Crustacea Decapoda: }
$$

Porcellanopagurus Filhol and Solitariopagurus Türkay (Paguridae), from the New Caledonian area, Vanuatu and the Marquesas: new records, new species. In: A. Crosnier (ed.), Résultats des campagnes MUSORSTOM, Volume 21. Mémoires du Muséum national d'Histoire naturelle, 184: 389-414.

, 2002, A review of the hermit crab (Decapoda: Anomura: Paguridea) fauna of southern Thailand, with particular emphasis on the Andaman Sea, and descriptions of three new species. In: N. Bruce, M. Berggren \& S. Bussarawit, (eds.), Biodiversity of Crustacea in the Andaman Sea - Proceedings of the Workshop held at the Phuket Marine
Biological Center (PMBC), Phuket, Thailand, 29 November - 20 December, 1998. Phuket Marine Biological Center Research Bulletin, Special Publication 23(2): 384-460.

, 2003. Illustrated keys to families and genera of the superfamily Paguroidea (Crustacea: Decapoda: Anomura), with diagnoses of genera of Paguridae. Memoirs of Museum Victoria, 60: 111-144.

-2004 . A reappraisal of the hermit crab genera Catapagurus A. Milne-Edwards and Hemipagurus Smith (Crustacea: Decapoda: Anomura: Paguridae), with the description of a new species. Zootaxa, 433: 1-16.

Schram, F. R., \& Koenemann, S., 2004. Developmental genetics and arthropod evolution: on body regions in Crustacea. In: $\mathrm{G}$. Scholtz, (ed.), Evolutionary Developmental Biology of Crustacea. Crustacean Issues 15. A.A. Balkema Publishers, Lisse, Abingdon, Exton (PA), Tokyo, 75-92.

Addresses: (TK) Natural History Museum and Institute, Chiba, 955-2 Aoba-cho, Chuo-ku, Chiba 260-8682, Japan; (PAM) Shannon Point Marine Center, Western Washington University, 1900 Shannon Point Road, Anacortes, WA 982219081B, U.S.A.

E-mails: (TK) komai@chiba-muse.or.jp; (PAM) hermit@fidalgo.net 